\title{
The relationship between Elder Risk Assessment (ERA) scores and cardiac revascularization: a cohort study in Olmsted County, Minnesota, USA
}

This article was published in the following Dove Press journal:

Clinical Interventions in Aging

13 September 2013

Number of times this article has been viewed

\author{
Saurabh Sharma' \\ Shruti Datta' \\ Shahyar Gharacholou',2 \\ Shahzad K Siddique ${ }^{3}$ \\ Stephen S Cha ${ }^{4}$ \\ Paul Y Takahashi ${ }^{1,5,6}$ \\ 'Department of Internal Medicine, \\ Mayo Clinic, Rochester, MN, USA; \\ ${ }^{2}$ Division of Cardiovascular Medicine, \\ Mayo Clinic, Rochester, MN, USA; \\ ${ }^{3}$ Shifa International Hospital, \\ Islamabad, Pakistan; ${ }^{4}$ Department \\ of Health Sciences Research, Mayo \\ Clinic, Rochester, MN, USA; ${ }^{5}$ Division \\ of Primary Care Internal Medicine, \\ Mayo Clinic, Rochester, MN, USA; \\ ${ }^{6}$ Kogod Center of Aging, Mayo Clinic, \\ Rochester, MN, USA
}

Correspondence: Paul Y Takahashi Mayo Clinic, 200 First Street SW, Rochester, MN 55905, USA

$\mathrm{Tel}+$ I 50728425 I I

Fax + I 5072660036

Email takahashi.paul@mayo.edu
Purpose: The aging population is predisposed to cardiovascular disease. Our goal was to determine the relationship between a higher Elder Risk Assessment (ERA) score and coronary artery bypass graft (CABG) or percutaneous coronary intervention (PCI), in adults over 60 years.

Methods: This was a retrospective cohort study in a primary care internal medicine practice. Patients included community-dwelling individuals aged 60 years or older on January 1, 2005. The primary outcome was a combined outcome of CABG and PCI in 2 years. The secondary outcome was mortality 5 years after CABG or PCI. The primary predictor variable was the score on the ERA Index, an instrument that predicts emergency room visits and hospitalization. The outcomes were obtained using administrative data from electronic medical records. The analysis included logistic regression, with odds ratios for the primary outcome and time-toevent analysis for mortality.

Results: The records of 12,650 patients were studied. A total of 902 patients $(7.1 \%)$ had either CABG or PCI, with an average age of 74.5 years ( \pm 8.3 years). There were 205 patients $(23 \%)$ who experienced CABG or PCI in the highest-score group (top 10\%) compared with 29 patients (3\%) in the lowest score group, for an odds ratio of $15.4 ; 95 \%$ confidence interval, 10.1-23.5. There was a greater association of revascularization events by increasing score group. We noted increased mortality by increasing ERA score, in patients undergoing CABG or PCI. The patients in the highest-scoring group had a 50\% 5-year survival rate compared with a 97\% 5-year survival rate in the lowest-scoring group $(P<0.001)$.

Conclusion: Older adults in the highest-ERA-scoring group had the highest utilization of CABG or PCI. Patients with high ERA scores undergoing coronary revascularization were also at the highest risk of mortality. Providers should be aware that higher ERA scores can potentially predict outcomes in high-risk patients.

Keywords: coronary bypass, geriatrics, mortality, percutaneous coronary intervention

\section{Introduction}

Frailty and high-risk, medically complex patients have attracted the attention of many providers because of the potential risk for future cardiovascular procedures as well as the potential for adverse events postprocedure. An estimated 83.6 million American adults (more than one in three) have coronary vascular disease (CVD). Of these, 42.2 million (50\%) are estimated to be $\geq 60$ years of age. ${ }^{1}$ One concern is the potential for concomitant CVD and frailty. Although there is no consensus on the definition of frailty, Fried's frailty definition incorporates a phenotype of low strength, slow gait speed, low physical activity, unintentional weight loss, and self-reported exhaustion. ${ }^{2}$ The estimation of frailty with a burden of comorbid conditions is another common method for determining the risk of adverse health outcomes. The Frailty Index includes a checklist of 70 items, with multiple 
comorbid conditions, disabilities, cognitive impairment, mood disturbance, and mobility limitations. ${ }^{3}$ The comorbid health burden has also been an important component of various hospital risk stratification models, such as the Ambulatory Care Group Risk Stratification Method developed by researchers at Johns Hopkins University. ${ }^{4}$ The relationship between frailty, as determined by the above methods assessing comorbid burden or phenotype, and future cardiovascular procedures remains an important discussion for providers.

Given the importance of the comorbid health burden and cardiovascular disease, we sought to understand the relationship between cardiovascular revascularization (coronary artery bypass graft $[\mathrm{CABG}]$ and percutaneous coronary intervention [PCI]) and the Elder Risk Assessment (ERA) Index, in adults over 60 years. We hypothesized that patients with a higher ERA score, who were most at risk for hospitalization, would be more likely to undergo cardiovascular revascularization than those patients with a lower score and without this frailty burden. To answer this question we performed a retrospective cohort study to determine the association between score on the ERA Index and the combined outcomes of CABG and PCI, in adults aged 60 years or older. As a secondary question, we sought to understand the relationship between ERA score and mortality in those patients who underwent cardiovascular revascularization.

\section{Design and methods Study design}

This was a retrospective cohort study. The study was approved by the Mayo Clinic Institutional Review Board.

\section{Setting}

The study was conducted in the Primary Care Internal Medicine (PCIM) Division at Mayo Clinic in Rochester, Minnesota, USA. The PCIM is a mixed internal medicine and geriatric outpatient practice that serves the residents of Olmsted County. In 2000, Olmsted County had a population of 124,277 , consisting of $90 \%$ white, $4 \%$ Asian, and $2 \%$ African American. ${ }^{5}$ The cohort was derived on January 1, 2005. Patients were followed for 2 years, from January 1, 2005 until December 31, 2006, to determine the occurrence of CABG or PCI. Mortality was followed for 5 years following a potential revascularization, until December 31, 2011, to determine the secondary outcome.

\section{Participants}

The inclusion criteria included all adults who were living in the community or in an assisted-living facility, aged
60 years or older, and who had given consent for medical record review. The patients were enrolled and had a primary care provider in PCIM. The exclusion criteria included those patients who did not give consent for medical record review and those patients who lived in a skilled-nursing facility on January 1, 2005.

\section{Outcome variables}

The primary outcome variable was a combined outcome of CABG and PCI. Each outcome of CABG and PCI was also analyzed separately for comparison. Both outcomes were derived from administrative billing data within the Mayo Clinic system. The secondary outcome was mortality in those subjects undergoing combined cardiovascular procedures. The mortality data was obtained from the electronic medical record (EMR) and was recorded from death within hospitals, nursing homes, and hospices within Olmsted County. Mortality statistics from a review of local newspapers and other resources are updated regularly in the EMR.

\section{Predictor variables}

The primary predictor variable was a calculated score on the ERA Index. This ERA was developed, using information from EMRs, to identify community-dwelling older adults at high risk for hospitalizations or emergency room visits. ${ }^{6}$ The ERA Index is a risk stratification instrument that uses several risk factors: age, marital status, hospital days in the preceding 2 years, and the comorbid medical illnesses diabetes mellitus, heart disease, stroke, emphysema, cancer (excluding nonmelanomatous skin cancer), and dementia. ${ }^{6}$ Patients were scored based on their individual factors. Individuals were categorized into five groups based on the ERA score, with the lowest scoring group reflecting the bottom quartile, second group the second quartile, third group the third highest quartile, fourth group between $75 \%-90 \%$ top score, and the highest scoring ERA group reflecting the top 10\%. The ERA not only predicts hospitalization, but also predicts other health outcomes, like hip fracture.

\section{Data collection}

The data were collected using the EMR at the Mayo Clinic in Rochester, MN, USA. The EMR is a comprehensive record of all hospital admissions, diagnoses, and comorbid health conditions within the institution. ${ }^{8}$ Mayo Clinic maintains all EMR information within one system, including hospital, emergency room, nursing home, and clinic visit information. Staff associates from the Division of Health Sciences Research extracted information from the EMR related to 
demographic characteristics, comorbid health problems, hospital utilization, and the outcomes of PCI and CABG.

\section{Data analysis}

We summarized the demographic differences and outcomes between participants who underwent a cardiovascular procedure and those who did not. The risk factors between the cardiovascular revascularization group and the nonrevascularization group were analyzed using either a Pearson $\chi^{2}$ test for proportional outcomes or a two-sample $t$-test if outcomes were continuous. We divided the cohort into five groups, according to the ERA scores: group A ( -7 to -1$)$; group B (0 to 3); group C (4 to 8); group D (9 to 15); and the highest group $\mathrm{E}(\geq 16)$. We used a logistic regression model that included groups B, C, D, and E, with the lowest scoring group (A) as the reference group. We computed the odds ratio (OR) with $95 \%$ confidence interval (CI) of undergoing cardiac revascularization within 2 years for each of these groups, using multiple logistic regression analyses for age, sex, and the ERA score group.

We calculated the sensitivity and specificity of predicting cardiac revascularization at each possible ERA cutoff score. A receiver operating characteristic curve was plotted, and the area under the curve was obtained. We identified the best cutoff point by using the ERA score that provided the highest sum of sensitivity and specificity. The secondary analysis included a time-to-event for mortality in those patients who underwent CABG or PCI. All information was analyzed using SAS version 9.3 software (SAS Institute Inc, Cary, NC, USA). Lastly, we analyzed overall mortality in the entire cohort using the ERA scoring group as a predictor and $\mathrm{CABG}$ or PCI as a time-dependent covariate. We stratified the mortality analysis into men and women for further comparison.

\section{Results}

\section{Patients}

On January 1, 2005, 13,457 patients 60 years of age or older were enrolled in the PCIM practice and eligible for study enrollment. Among the eligible patients, 807 patients (6\%) did not agree to medical record review, which led to a total study cohort of 12,650 patients $(94 \%)$. The patients with CABG or PCI revascularization were older age (74 compared with $72.6 \mathrm{yrs}$ ), male, and white. The coronary revascularization group was also more likely to have all potential vascular comorbidities. The demographic characteristics, comorbid health characteristics, and ERA score groups of the cohort are listed in Table 1. The specific characteristics for individual outcomes of CABG alone and PCI alone are also listed in Table 1.

\section{Era scores and outcome of CABG and PCl}

Overall, 902 of the 12,650 patients (7.1\%) had PCI or CABG or both procedures in the 2 years following January 1, 2005. An increase in ERA score group corresponded with the increased odds of performing CABG or PCI. Specifically, in the group with an ERA score $\geq 16,23 \%$ of the participants underwent a procedure compared with only $3 \%$ in the lowest scoring group $(-7$ to -1$)(P<0.001)$. Comparing the highest scoring ERA group with the lowest scoring group, we found incremental increases in OR. The OR for the highest group compared with the lowest group was 15.4 (95\% CI, 10.1-23.5). In a similar fashion, increasing ERA score significantly increased $\mathrm{CABG}$ use alone $(P<0.001)$ and also PCI use alone $(P<0.001)$, as noted in Table 1. The ORs adjusted for age and sex are noted in Table 2. When plotting the ERA score versus the combined outcome of CABG and PCI, the receiver operator curve revealed an optimal ERA score of 4 , with a sensitivity of 0.80 and a specificity of 0.51 . The area under the curve was 0.71 (95\% CI, 0.69-0.73) (Figure 1).

\section{CABG, $\mathrm{PCl}$, and survival}

Among the 902 patients undergoing PCI or CABG, survival over the following 5 years showed a significant impact of the ERA score on survival. Patients in the group with the highest ERA score, of $\geq 16$ had a 5-year survival of $50 \%$ compared with an over $97 \%$ survival in patients with ERA scores $<-1$. These results are noted on the Kaplan-Meier curve (Figure 2) $(P<0.001)$. We noted a decreased survival with increasing ERA scoring categories (Table 3 ). Table 4 presents the overall mortality in the entire cohort of 12,650 participants. We noted an increased mortality with increasing ERA score and that CABG or PCI was not a significant factor for mortality in this model (either protective or harmful). In the stratified analysis for male and female sex, there was no mortality difference between men and women within all ERA scoring categories. At 5 years, patients with an ERA score $\geq 16$ had a survival, of 0.497 (95\% CI 0.416 to 0.595$)$ in males and of 0.438 (95\% CI 0.342 to 0.560 ) in females. Thus, the survival at 5 years overlaps between $50 \%$ to $44 \%$ in men and women respectively.

\section{Discussion}

In this retrospective cohort study of 12,650 patients, an increasing ERA score predicted CABG and PCI utilization. Almost $23 \%$ of all patients with an ERA score 
Table I Baseline characteristics of 12,650 adults over 60 who underwent coronary artery bypass grafting, percutaneous coronary interventions or both

\begin{tabular}{|c|c|c|c|c|c|c|c|c|c|}
\hline Variable & $\begin{array}{l}\text { None } \\
(\mathbf{N}=1 \mathrm{I}, \mathbf{7 4 8})\end{array}$ & $\begin{array}{l}\text { CABG } \\
\text { or PCI } \\
(\mathbf{N}=902)\end{array}$ & $P$-value & $\begin{array}{l}\text { None } \\
(\mathbf{N}=|2,| 45)\end{array}$ & $\begin{array}{l}\text { CABG } \\
(N=505)\end{array}$ & $P$-value & $\begin{array}{l}\text { None } \\
(N=12, \mid 48)\end{array}$ & $\begin{array}{l}\mathrm{PCl} \\
(\mathrm{N}=502)\end{array}$ & $P$-value \\
\hline \multicolumn{10}{|l|}{ Demographics } \\
\hline Age, continuous & $72.6 \pm 8.88$ & $74.5 \pm 8.29$ & $<0.001$ & $72.65 \pm 8.88$ & $74.7 \pm 7.86$ & $<0.001$ & $72.67 \pm 8.85$ & $74.28 \pm 8.70$ & $<0.001$ \\
\hline $\begin{array}{l}\text { Age (decile), } \\
\mathrm{n}(\%)\end{array}$ & & & $<0.001$ & & & $<0.001$ & & & 0.004 \\
\hline Age $60-69$ & $5044(43)$ & $283(3 I)$ & & $5189(43)$ & 138 (27) & & $5150(42)$ & 177 (35) & \\
\hline Age 70-79 & 3918 (33) & $365(40)$ & & 4057 (33) & $226(45)$ & & $4106(34)$ & $177(35)$ & \\
\hline Age 80-89 & $2305(20)$ & $223(25)$ & & $2398(20)$ & $130(26)$ & & 240 I (20) & $127(25)$ & \\
\hline Age 90+ & $48 I(4)$ & $31(3)$ & & $501(4)$ & II (2) & & 49I (4) & $21(4)$ & \\
\hline Race, white & $10650(91)$ & $858(95)$ & & II 022 (9I) & $486(96)$ & & II 035 (9I) & $473(94)$ & \\
\hline Sex, n (\%) & & & $<0.001$ & & & $<0.001$ & & & $<0.001$ \\
\hline Female & 6940 (59) & $327(36)$ & & $7106(59)$ & I6I (32) & & $7060(58)$ & $207(4 I)$ & \\
\hline Male & $4808(4 I)$ & $575(64)$ & 0.003 & $5039(4 I)$ & $344(68)$ & 0.009 & $5088(42)$ & $295(59)$ & 0.1 \\
\hline $\begin{array}{l}\text { Marital status, } \\
\mathrm{n}(\%)\end{array}$ & & & 0.27 & & & 0.19 & & & 0.68 \\
\hline Divorced & $828(7)$ & $58(6)$ & & $858(7)$ & $28(6)$ & & $851(7)$ & $35(7)$ & \\
\hline Married & $765 I$ (65) & $612(68)$ & & $7916(65)$ & 347 (69) & & 7930 (65) & $333(66)$ & \\
\hline Single & $761(6)$ & $44(5)$ & & $784(6)$ & $21(4)$ & & $781(6)$ & $24(5)$ & \\
\hline Widowed & $2465(2 I)$ & $186(2 \mid)$ & & $2543(21)$ & $108(2 I)$ & & $2542(2 I)$ & $109(22)$ & \\
\hline \multicolumn{10}{|l|}{ ERA score, n (\%) } \\
\hline Score -7 to -1 & $1697(14)$ & $29(3)$ & $<0.001$ & $1718(14)$ & $8(2)$ & $<0.001$ & $1706(14)$ & $20(4)$ & $<0.001$ \\
\hline Score $0-3$ & $4284(36)$ & 149 (I7) & & $4355(36)$ & $78(15)$ & & $4357(36)$ & $76(15)$ & \\
\hline Score 4-8 & $2887(25)$ & $275(30)$ & & $3006(25)$ & I56 (3I) & & $3009(25)$ & $153(30)$ & \\
\hline Score 9-15 & $1901(16)$ & $244(27)$ & & 2009 (17) & $136(27)$ & & $2013(17)$ & I32 (26) & \\
\hline Score 16+ & $979(8)$ & $205(23)$ & & $1057(9)$ & $127(25)$ & & $1063(9)$ & $|2|(24)$ & \\
\hline \multicolumn{10}{|c|}{ Comorbid conditions, n (\%) } \\
\hline Cancer & $2742(23)$ & $246(27)$ & 0.007 & $2847(23)$ & |4| (28) & 0.02 & $2847(23)$ & $|4|$ (28) & 0.016 \\
\hline Diabetes & $2769(24)$ & $313(35)$ & $<0.001$ & $2893(24)$ & 189 (37) & $<0.001$ & $2913(24)$ & $169(34)$ & $<0.001$ \\
\hline Stroke & $52(0)$ & II (I) & 0.001 & $56(0)$ & $7(1)$ & 0.004 & $56(0)$ & $7(1)$ & 0.004 \\
\hline $\begin{array}{l}\text { Peripheral } \\
\text { vascular disease }\end{array}$ & $909(8)$ & $191(2 \mid)$ & $<0.001$ & $983(8)$ & 117 (23) & $<0.001$ & $1003(8)$ & $97(19)$ & $<0.001$ \\
\hline Renal insufficiency & $1156(10)$ & $178(20)$ & $<0.001$ & $1225(10)$ & $109(22)$ & $<0.001$ & $1232(10)$ & $102(20)$ & $<0.001$ \\
\hline $\mathrm{CHF}$ & $938(8)$ & $253(28)$ & $<0.001$ & $102 \mid(8)$ & $170(34)$ & $<0.001$ & $1062(9)$ & $129(26)$ & $<0.001$ \\
\hline $\begin{array}{l}\text { Venous } \\
\text { insufficiency }\end{array}$ & $540(5)$ & $4 \mid(5)$ & 0.94 & $558(5)$ & $23(5)$ & 0.97 & $555(5)$ & $26(5)$ & 0.52 \\
\hline Carotid disease & $337(3)$ & $72(8)$ & $<0.001$ & $357(3)$ & $52(10)$ & $<0.001$ & $373(3)$ & $36(7)$ & $<0.001$ \\
\hline Hypertension & $8068(69)$ & $753(83)$ & $<0.001$ & $8394(69)$ & $427(85)$ & $<0.001$ & 8405 (69) & $416(83)$ & $<0.001$ \\
\hline Hyperlipidemia & $7360(63)$ & $774(86)$ & $<0.001$ & $7680(63)$ & $454(90)$ & $<0.001$ & $7712(63)$ & $422(84)$ & $<0.001$ \\
\hline Stroke & $1339(11)$ & $208(23)$ & $<0.001$ & $1412(12)$ & $135(27)$ & $<0.001$ & $1439(12)$ & $108(22)$ & $<0.001$ \\
\hline TIA & $843(7)$ & $144(16)$ & $<0.001$ & $898(7)$ & $89(18)$ & $<0.001$ & $910(7)$ & $77(15)$ & $<0.001$ \\
\hline Myocardial & $2938(25)$ & 687 (76) & $<0.001$ & 3201 (26) & $424(84)$ & $<0.001$ & $3258(27)$ & 367 (73) & $<0.001$ \\
\hline
\end{tabular}

Notes: The table describes the demographic, frequency of comorbidity, and ERA score predictor for the combined outcomes of CABG and/or PCI, CABG alone, and PCI alone $(n=12,650)$. The presence of most comorbid illness and higher ERA scores were higher in patients undergoing CABG or PCl compared with no procedure, in most instances.

Abbreviations: CABG, coronary artery bypass graft; CHF, congestive heart failure; ERA, Elders Risk Assessment; PCl, percutaneous coronary intervention; TIA, transient ischemic attack.

$\geq 16$ underwent either CABG or PCI in the following 2 years. These findings are not completely unexpected, as higher ERA scores are associated with future hospitalization ${ }^{6}$ and likely measure some degree of frailty. Frailty, the loss of physiologic organ reserve leading to disease, occurs commonly with increasing age and chronic illness, including heart disease. ${ }^{9}$
An association between frailty and increased coronary disease has been reported often. In the Zutphen Elderly Study of 450 adults aged $69-89$ years, $62 \%$ of frail men were found to have CVD compared with only $28 \%$ of nonfrail men (OR $4.1 ; 95 \%$ CI, 1.8-9.3). ${ }^{10}$ In a cardiovascular health study of 4,753 adults, the investigators found that patients who had 
Table 2 Odds of CABG or PCI, by ERA score and demographic predictors, in 12,650 patients over 60

\begin{tabular}{llllll}
\hline Parameter & Estimate & $\begin{array}{l}\text { Odds } \\
\text { ratio }\end{array}$ & \multicolumn{2}{l}{$\mathbf{9 5 \%} \mathbf{C l}$} & P-value \\
\cline { 5 - 6 } & & & Lower & Upper & \\
\hline Intercept & $-3.8 \mathrm{I}$ & & & & $<0.000$ I \\
Score 0-3 & 0.82 & 2.28 & 1.52 & 3.41 & $<0.000$ I \\
Score 4-8 & 1.83 & 6.25 & 4.20 & 9.29 & $<0.000$ I \\
Score 9-15 & 2.16 & 8.66 & 5.78 & 12.99 & $<0.000$ I \\
Score 16+ & 2.74 & 15.42 & 10.12 & 23.50 & $<0.000$ I \\
Male & 0.90 & 2.45 & 2.12 & 2.83 & $<0.000$ I \\
Age & -0.01 & 0.99 & 0.98 & 1.00 & 0.0085 \\
\hline
\end{tabular}

Notes: The full multivariable model including age and sex indicated that higher ERA scores had a higher odds of CABG or PCl, after adjustment for age and sex. Abbreviations: $\mathrm{CABG}$, coronary artery bypass graft; $\mathrm{Cl}$, confidence interval; ERA, Elder Risk Assessment; $\mathrm{PCl}$, percutaneous coronary intervention.

CVD were 2.79 times (95\% CI, 2.12-3.67) more likely to be frail. ${ }^{11}$ The Women's Health and Aging Studies (WHAS) I and II of 670 community-dwelling elders showed similar predictive associations between frailty and CVD. ${ }^{12,13}$ The ERA is likely associated with a phenotype that places the individual at risk for coronary revascularization. The ERA Index is not a direct measure of frailty; however, it does predict hospitalization, which likely reflects a phenotype that mirrors frailty with older age, previous hospitalization, and comorbid burden.

The relationship between risk factors and the instruments calculating scores for risk factors and coronary revascularization is important for clinical providers. Patients often

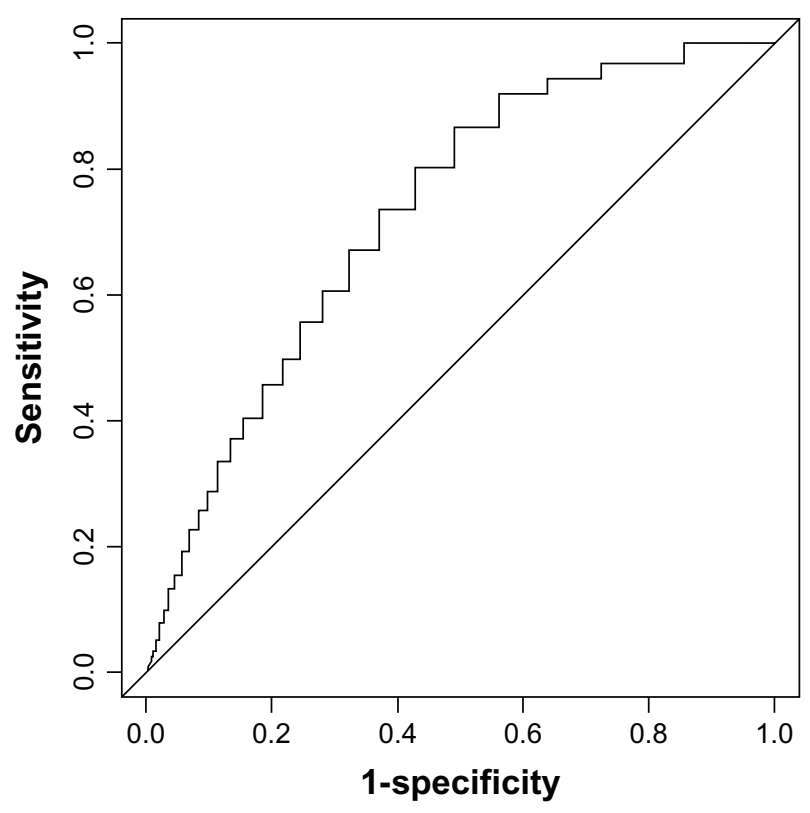

Figure I Receiver operator curve for Elder Risk Assessment Score with the outcome of coronary artery bypass graft or percutaneous coronary intervention. Note: The AUC is $0.7 \mathrm{I}(95 \% \mathrm{Cl}, 0.69-0.73)$.

Abbreviations: $\mathrm{AUC}$, area under the curve; $\mathrm{Cl}$, confidence interval.

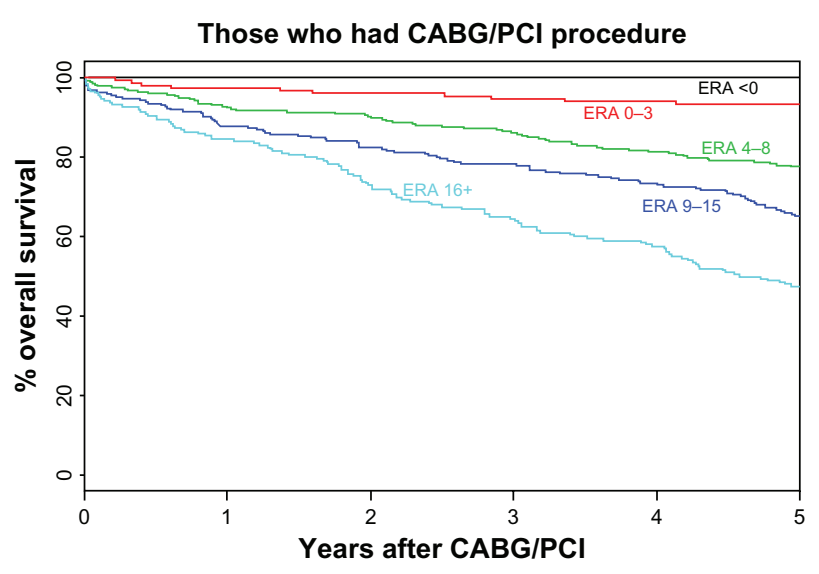

Figure $\mathbf{2}$ Time to mortality for 902 patients who underwent coronary artery bypass graft and percutaneous coronary intervention, according to ERA Score.

Notes: The figure shows the Kaplan-Meier survival curves for patients who had undergone CABG or $\mathrm{PCl}$. The higher ERA scores had lower percent survival at 5 years.

Abbreviations: CABG; coronary artery bypass graft; ERA, Elder Risk Assessment; $\mathrm{PCl}$, percutaneous coronary intervention.

suffer multiple illnesses when they undergo coronary revascularization. A comparison study of frail patients versus nonfrail patients undergoing PCI showed that one-fifth of older patients were frail at the time of PCI and possessed a greater comorbid burden, angiographic disease severity, and poorer health status than did the nonfrail adults. ${ }^{14}$ Investigators have developed other clinical instruments that measure this comorbid burden and can help providers assess potential risk. The Framingham heart predictive tool is the most widely used instrument in clinical practice to help predict heart disease and has been validated in multiple populations. ${ }^{15}$ The Framingham risk score accounts for age, sex, blood pressure, smoking status, and cholesterol. The Framingham risk score can also include other biomarkers that can add to its predictive value. ${ }^{16}$ The primary weakness of the Framingham risk score relates to its reliance on active data and cholesterol levels to predict risk. The ERA Index, while not a specific instrument for CABG and PCI, can certainly

Table 3 Hazard ratios for overall mortality in 902 patients who underwent coronary artery bypass or percutaneous coronary intervention, by ERA score

\begin{tabular}{|c|c|c|c|c|c|}
\hline \multirow[t]{2}{*}{ Parameter } & \multirow[t]{2}{*}{ Estimate } & \multirow{2}{*}{$\begin{array}{l}\text { Hazard } \\
\text { ratio }\end{array}$} & \multicolumn{2}{|l|}{$95 \% \mathrm{Cl}$} & \multirow[t]{2}{*}{$P$-value } \\
\hline & & & Lower & $\overline{\text { Upper }}$ & \\
\hline Score 0-3 & 1.29 & 3.63 & 0.49 & 27.20 & 0.2093 \\
\hline Score 4-8 & 2.39 & 10.90 & 1.52 & 78.26 & 0.0175 \\
\hline Score 9-15 & 2.98 & 19.65 & 2.75 & 140.57 & 0.0030 \\
\hline Score $16+$ & 3.50 & 33.00 & 4.62 & 235.90 & 0.0005 \\
\hline
\end{tabular}

Notes: The hazard ratios for mortality increased with increasing ERA score in patients undergoing CABG or $\mathrm{PCl}(\mathrm{n}=902)$.

Abbreviations: $\mathrm{CABG}$, coronary artery bypass graft; $\mathrm{Cl}$, confidence interval; $\mathrm{ERA}$, Elder Risk Assessment; $\mathrm{PCl}$, percutaneous coronary intervention. 
Table 4 Hazard ratios for overall mortality for all 12,650 primary care patients, by ERA score with added coronary revascularization term

\begin{tabular}{|c|c|c|c|c|c|}
\hline \multirow[t]{2}{*}{ Parameter } & \multirow[t]{2}{*}{ Estimate } & \multirow{2}{*}{$\begin{array}{l}\text { Hazard } \\
\text { ratio }\end{array}$} & \multicolumn{2}{|l|}{$95 \% \mathrm{Cl}$} & \multirow[t]{2}{*}{$P$-value } \\
\hline & & & Lower & $\overline{\text { Upper }}$ & \\
\hline Score 0-3 & 1.48 & 4.38 & 3.20 & 5.98 & $<0.0001$ \\
\hline Score 4-8 & 2.54 & 12.72 & 9.37 & 17.28 & $<0.0001$ \\
\hline Score 9-15 & 3.22 & 24.97 & 18.40 & 33.89 & $<0.0001$ \\
\hline Score 16+ & 3.92 & 50.16 & 36.89 & 68.19 & $<0.0001$ \\
\hline $\mathrm{CABG}$ or $\mathrm{PCl}$ & 0.08 & 1.08 & 0.97 & 1.20 & 0.1823 \\
\hline
\end{tabular}

Notes: The table depicts the hazard ratios for all patients $(n=12650)$ for mortality and higher ERA scores. The higher ERA scores resulted in higher hazard ratios but were not influenced by CABG or PCl.

Abbreviations: $\mathrm{CABG}$, coronary artery bypass graft; $\mathrm{Cl}$, confidence interval; ERA, Elder Risk Assessment; $\mathrm{PCl}$, percutaneous coronary intervention.

perform well to help predict future revascularization. The potential advantage of using ERA scores is related to the use of a single score that can help clinicians gauge the potential risk for hospitalization and cardiovascular revascularization. Using this single instrument may also predict other health outcomes, which may improve its clinical utility. This universal utility differs from disease-specific instruments, like the Framingham risk score, which may have higher sensitivity and specificity for PCI or CABG.

In our secondary analysis of patients who underwent CABG or PCI, we observed a relationship between increasing ERA score and rising mortality over the following 5 years. Previous investigators have shown increases in mortality with increasing frailty. The Beaver Dam Eye Study followed 2,962 community-dwelling elders for 4.5 years and found that an increase of one level in the Klein four-level Frailty Index resulted in an increase of $56 \%$ in all-cause mortality. ${ }^{17}$ In our previous work with the ERA Index, we found among patients over the age of 60 years, a 50-fold increased risk of mortality in high-ERA-scoring patients compared with that in lowscoring patients. ${ }^{18}$ Thus, our finding that higher ERA scores predict mortality is not unexpected in this higher-comorbidity group of CABG or PCI patients. However, due to the magnitude of mortality, with only a $50 \% 5$-year survival rate in patients with ERA scores over 16, health service providers should have some caution when recommending coronary revascularization to patients. These findings emphasize that the prognosis of patients with the highest score should be discussed prior to coronary revascularization.

This study has some limitations that are inherent within a retrospective cohort study. There are risks of missing outcomes if patients seek hospital or emergency room care in outside institutions. It is possible that patients with lower ERA scores are more mobile; thus, we may have missed outcomes such as hospitalizations in other medical systems. This bias could result in higher hospitalization or ER visit rates among the less mobile, more complex older adults compared with less complex, lower-scoring ERA patients. Pragmatically, most patients, including patients with lower ERA scores, have received care within their primary care medical system, and the outcomes should be captured. It is also possible that the scoring system for the ERA was not accurate because of misentered diagnosis codes or diagnostic codes that were not captured; however, there should not be a differential effect of this potential bias among ERA scoring groups. The population in Olmsted County consists of mostly white patients; thus, it may not generalize to other clinical practices. Further studies are needed to be able to project the outcomes in a broader ethnic mix of patients.

The clinical and research implications provide some insight into potential future work. The ERA is an electronic score that is obtained for each patient and is updated without input from staff. ${ }^{6}$ In this study, we found that ERA predicts $\mathrm{CABG}$ or PCI. It is quite possible that other administrative hospital risk scores would provide similar clinical utility. Providers can integrate common administrative demographics and medical diagnoses into a risk score. This knowledge may change the risk-factor management of, for example, blood pressure and cholesterol, for patients at the highest risk for future revascularization. Second, in patients with ERA scores $\geq 16$, providers need to understand that the mortality risks within 5 years after coronary revascularization may only be $50 \%$. In this population, adding CABG or PCI did not modify survival; thus, CABG or PCI would primarily be used for symptom management.

\section{Acknowledgments}

We would like to acknowledge the Department of Internal Medicine for supporting this work. We also acknowledge Gladys Hebl, of Grant and Publication Support Services, for help with preparation of the manuscript.

\section{Disclosure}

The authors report no conflicts of interest in this work.

\section{References}

1. American Heart Association. Statistical Fact Sheet: Older Americans and Cardiovascular Diseases. Dallas, TX: American Heart Association; Statistical fact sheet 2013. Available from: http://www.heart.org/idc/ groups/heart-public/@wcm/@sop/@smd/documents/downloadable/ ucm_319574.pdf. Accessed August 5, 2013.

2. Fried LP, Tangen CM, Walston J, et al; Cardiovascular Health Study Collaborative Research Group. Frailty in older adults: evidence for a phenotype. J Gerontol A Biol Sci Med Sci. 2001;56(3):M146-M156. 
3. Rockwood K, Mitnitski A. Frailty in relation to the accumulation of deficits. J Gerontol A Biol Sci Med Sci. 2007;62(7):722-727.

4. Weiner JP, Starfield BH, Steinwachs DM, Mumford LM. Development and application of a population-oriented measure of ambulatory care case-mix. Med Care. 1991;29(5):452-472.

5. factfinder2.census.gov [homepage on the Internet]. Profile of general demographic characteristics: 2000. US Census Bureau; 2000 [cited May 4, 2010]. Available from: http://factfinder2.census.gov/faces/ tableservices/jsf/pages/productview.xhtml?pid=DEC_00_SF1_ DP1\&prodType=table. Accessed August 5, 2013.

6. Crane SJ, Tung EE, Hanson GJ, Cha S, Chaudhry R, Takahashi PY. Use of an electronic administrative database to identify older community dwelling adults at high-risk for hospitalization or emergency department visits: the elders risk assessment index. BMC Health Serv Res. 2010;10:338.

7. Albaba M, Cha SS, Takahashi PY. The Elders Risk Assessment Index, an electronic administrative database-derived frailty index, can identify risk of hip fracture in a cohort of community-dwelling adults. Mayo Clin Proc. 2012;87(7):652-658.

8. St Sauver JL, Grossardt BR, Yawn BP, et al. Data resource profile: the Rochester Epidemiology Project (REP) medical records-linkage system. Int J Epidemiol. 2012;41(6):1614-1624.

9. Rockwood K, Mitnitski A. Frailty defined by deficit accumulation and geriatric medicine defined by frailty. Clin Geriatr Med. 2011;27(1): 17-26.

10. Chin A, Paw MJ, Dekker JM, Feskens EJ, Schouten EG, Kromhout D. How to select a frail elderly population? A comparison of three working definitions. J Clin Epidemiol. 1999;52(11):1015-1021.
11. Newman AB, Gottdiener JS, Mcburnie MA, et al; Cardiovascular Health Study Research Group. Associations of subclinical cardiovascular disease with frailty. J Gerontol A Biol Sci Med Sci. 2001;56(3): M158-M166.

12. Bandeen-Roche K, Xue QL, Ferrucci L, et al. Phenotype of frailty: characterization in the women's health and aging studies. $J$ Gerontol A Biol Sci Med Sci. 2006;61(3):262-266.

13. Chaves PH, Semba RD, Leng SX, et al. Impact of anemia and cardiovascular disease on frailty status of community-dwelling older women: the Women's Health and Aging Studies I and II. J Gerontol A Biol Sci Med Sci. 2005;60(6):729-735.

14. Gharacholou SM, Roger VL, Lennon RJ, et al. Comparison of frail patients versus nonfrail patients $\geq 65$ years of age undergoing percutaneous coronary intervention. Am J Cardiol. 2012;109(11): $1569-1575$.

15. D'Agostino RB, Grundy S, Sullivan LM, Wilson P; CHD Risk Prediction Group. Validation of the Framingham coronary heart disease prediction scores: results of a multiple ethnic groups investigation. JAMA. 2001;286(2):180-187.

16. Yeboah J, McClelland RL, Polonsky TS, et al. Comparison of novel risk markers for improvement in cardiovascular risk assessment in intermediate-risk individuals. JAMA. 2012;308(8):788-795.

17. Klein BE, Klein R, Knudtson MD, Lee KE. Frailty, morbidity and survival. Arch Gerontol Geriatr. 2005;41(2):141-149.

18. Takahashi PY, Tung EE, Crane SJ, Chaudhry R, Cha S, Hanson GJ. Use of the elderly risk assessment (ERA) index to predict 2-year mortality and nursing home placement among community dwelling older adults. Arch Gerontol Geriatr. 2012;54(1):34-38.
Clinical Interventions in Aging

\section{Publish your work in this journal}

Clinical Interventions in Aging is an international, peer-reviewed journal focusing on evidence-based reports on the value or lack thereof of treatments intended to prevent or delay the onset of maladaptive correlates of aging in human beings. This journal is indexed on PubMed Central, MedLine, the American Chemical Society's 'Chemical Abstracts

\section{Dovepress}

Service' (CAS), Scopus and the Elsevier Bibliographic databases. The manuscript management system is completely online and includes a very quick and fair peer-review system, which is all easy to use. Visit http://www.dovepress.com/testimonials.php to read real quotes from published authors. 